\title{
Treatment of Cherubism with Salmon Calcitonin: A Case Report
}

\author{
Osman A. Etoz \\ Dogan Dolanmazb \\ Omer Gunhanc
}

\begin{abstract}
Cherubism is a familial disease of the jaws which is inherited via autosomal dominant manner. Typical features of cherubism include a painless bilateral, symmetrical enlargement of the jaws, misalignment of teeth, and intra-osseous central giant cell granuloma-like lesions, which are usually evident in early childhood. Treatment of cherubism consists of local curettage of the lesions, jaw contouring, intralesional steroid injections, and systemic calcitonin administration as well. Calcitonin therapy for central giant cell granuloma of the jaws is well documented, and favorable results have been achieved. However, fewer reports have been presented in regard to calcitonin administration for cherubism. In the present report, a 14-year-old boy with cherubism who had intra-osseous cherubic lesions in his mandible was treated with an administration of 200 IU systemic calcitonin every other day via his nasal passage for duration of more than two years. After 30 months of calcitonin therapy, the lesions in the mandible were significantly regressed, and calcitonin application was ceased. Despite some drawbacks, such as unpredictable efficient absorption and patient tolerability, nasal administration is the easiest way to use calcitonin therapy on children. In this report, every-other-day applications of calcitonin increased patient tolerability and might be considered as an effective treatment for mild cherubic lesions. (Eur J Dent 2011;5:486-491)
\end{abstract}

Key words: Cherubism; Salmon calcitonin; Central giant cell granuloma.

a Assistant Professor, Erciyes University, Faculty of Dentistry, Department of Oral and Maxillofacial Surgery, Kayseri, Turkey.

b Associate Professor, Selcuk University, Faculty of Dentistry, Department of Oral and Maxillofacial Surgery, Konya, Turkey.

Professor, Gülhane Military Medical Academy and Medical Faculty, Department of Pathology, Ankara, Turkey.

- Corresponding author: Dr. Osman Etoz Erciyes Universitesi, Dis Hekimligi Fakultesi, Cerrahi Bolumu, 38039 Melikgazi, Kayseri, Turkey Phone: +903524374937

Fax: +90 3524380657

E-mail: osmanetoz@yahoo.com

\section{INTRODUCTION}

Cherubism is a familial disorder of the jaws, which was first identified by Jones in 1933. ${ }^{1}$ The term "cherubism" has arisen from the characteristic cherubic appearance of the patients. Cherubism is an autosomal dominant disease, and mutation of the exon 9 of the SH3BP2 gene has been identified in cherubism patients. Although penetrance of cherubism is known to be $100 \%$ for males and $50 \%$ to $70 \%$ for females, some clinical studies have shown that mutation in this gene does not have $100 \%$ penetrance in males. ${ }^{2-4} \mathrm{Com}-$ mon clinical and radiographic signs of patients 
with cherubism are painless bilateral expansion of the jaws, displaced and/or missing teeth or tooth germs, and multilocular well-defined radiolucent lesions. Histopathologic features of the aforementioned lesions are similar to central giant cell granuloma (CGCG). Despite their stromal structure, cherubism lesions are spongier than CGCG lesions, and eosinophilic fibrolitic thickening has been evident. ${ }^{5}$ However, cherubism and CGCG lesions have similar findings and similar treatment options. Conventional treatment of CGCG comprises local curettage and long-term follow-up. Despite the high success rate of surgical interventions in the management of CGCG, conservative approaches like intralesional steroid injections, ${ }^{6}$ subcutaneous administration of $\alpha$-interferon following surgery, ${ }^{7}$ and systemic calcitonin therapy ${ }^{8}$ have been advocated, and favorable results have been achieved.

It has been reported that calcitonin therapy is a feasible treatment option in the management of CGCG, especially for larger aggressive or multiple lesions. ${ }^{9}$ However, few reports have been published with regard to successfully treated CGCGlike lesions of cherubism by calcitonin administration. In this case report, treatment of cherubism with 200 IU salmon calcitonin via nasal administration is presented.

\section{CASE REPORT}

A 14-year-old boy was referred to our clinic with a complaint of painless bilateral symmetric thickening of the lower jaw and dental disharmony. Extra-oral view of the patient exhibited bilateral swelling in the angular region of the mandible, which was relatively resolved with age, and bilateral exophtalmus and bulb displacement (Figures 1 and 2). Facial signs in the patient were present for more than 10 years. Panoramic radiograph of the patient revealed bilateral thickening of the mandible, irregular multiple multilocular radiolucent areas and displaced teeth and tooth germs, as well as missing permanent teeth (Figure 3). The boundaries of the lesions were also determined by computerized tomography (CT) scan (Figure 4). Serum levels of parathyroid hormone and alkaline phosphatase were in the range of normal values. An incisional biopsy was performed under local anesthesia. The histopathologic characteristic of the lesion was consistent with CGCG, which dis- plays oval-shaped fibrohistiocytic stromal cells and osteoclast-like multinuclear cells on hemorrhagic ground (Figure 5). The history of the patient and younger photographs of him revealed a significant regression of swellings over the course of growth (Figure 1B).

According to the history of the patient, clinical and laboratory findings, and radiographic and histological examinations, a final diagnosis was cherubism. The family of the patient was informed about the prognosis of the disease because the other family members were free of cherubism

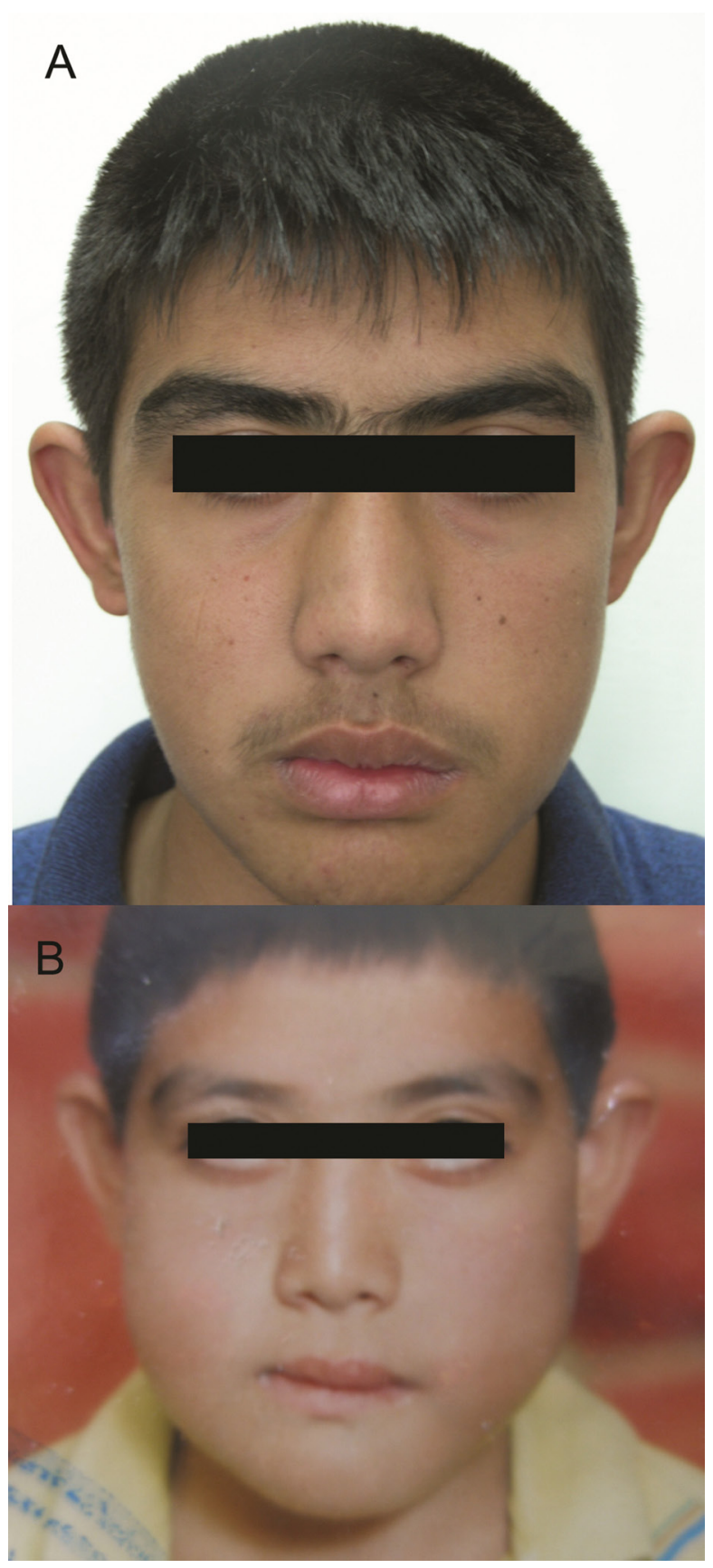

Figure 1. Frontal views of the patient before calcitonin therapy (A) and at the time of early childhood (B). 
symptoms. Calcitonin therapy was initialized with salmon calcitonin every other day by use of a nasal spray (Calcitonina Hubber 200 IU, ICN Iberica, Spain). Periodical radiographic follow-up was performed in order to evaluate the efficacy of the treatment. After 30 months of treatment, significant radiographic improvement was observed and calcitonin therapy was ceased (Figures 6 and 7).

\section{DISCUSSION}

The main findings of cherubism are bilateral symmetrical swelling in the angular region of the face and intra-osseous CGCG-like lesions in the jaws. Cherubism is a familial disorder, which has also been reported as a type of fibrous dysplasia of the jaws. ${ }^{10} \mathrm{~A}$ possible etiological pathway of cherubism and related CGCG lesions is related to dysregulation of mesenchymal bone subsequent to a disturbed cap stage of the second and third molar, which is induced by mutation in the SH3BP2 gene. ${ }^{11}$ Although multiple family members in the same generation may be affected due to the autosomal dominant characteristic of the disease, a lack of familial background could be observed ${ }^{12,13}$ as in the present case.

Conventional treatment of cherubism includes jaw contouring, curettage of the lesions, and management of dental disharmony. Although there are many reports concerning regression of the cherubic lesions in advanced ages, ${ }^{13}$ CGCG-like lesions in cherubism usually need to be treated, and favorable results have been obtained with calcitonin administration in the management of CGCG. 2,9,14 Calcitonin therapy for CGCG was first described by Harris in $1993 .{ }^{8}$ The therapeutic effects of calcitonin may act on calcitonin receptors in the giant cells of the CGCG, and increased osteoclastic activity in CGCG has been thought to be antagonized via calcitonin therapy. ${ }^{14,15}$ The use of calcitonin therapy for cherubism has been rarely documented. In an in vitro study, the positive effects of calcitonin on bone resorption within cherubic lesions was proven. ${ }^{16}$ Lannon and Earley ${ }^{17}$ observed the therapeutic failure of $100 \mathrm{IU}$ calcitonin therapy via daily subcutaneous injections for 6 months, and reported that no regression was observed. They stated that failure of calcitonin therapy is related to poor compliance by the patient, as well as the relatively short treatment period, and they concluded that improved patient compliance might be obtained by using the intranasal method. Hart et $\mathrm{al}^{18}$ performed one year of calcitonin therapy for cherubism via nasal administration, but they had to stop the treatment because of nausea. In a recent report, de Lange et $\mathrm{al}^{2}$ performed daily administration of 200 IU calcitonin via nasal spray for a 15-month period in a boy with cherubism and observed considerable regression of the lesion after cessation of therapy. Similar to the manner of therapy used by de Lange et $\mathrm{al}^{2}{ }^{2}$ in the present case, calcitonin was administered via the nasal passage for duration of more than two years.

The severity of cherubic lesions varies case to case, and its severity has been classified by previous authors (grades 1, 2 and 3, according to severity of lesions). ${ }^{10,19,20}$ The course of treatment may vary according to the size of the lesion. The present case might be considered as a grade 1 case of cherubism due to the fact that bilateral lesions occurred only in the posterior mandible, and the duration of the treatment was longer as well. No side effects were observed during the treatment period.

The dose, type, and administration method of calcitonin has been documented in many reports. $2,8,9,14$ Since calcitonin was first used for

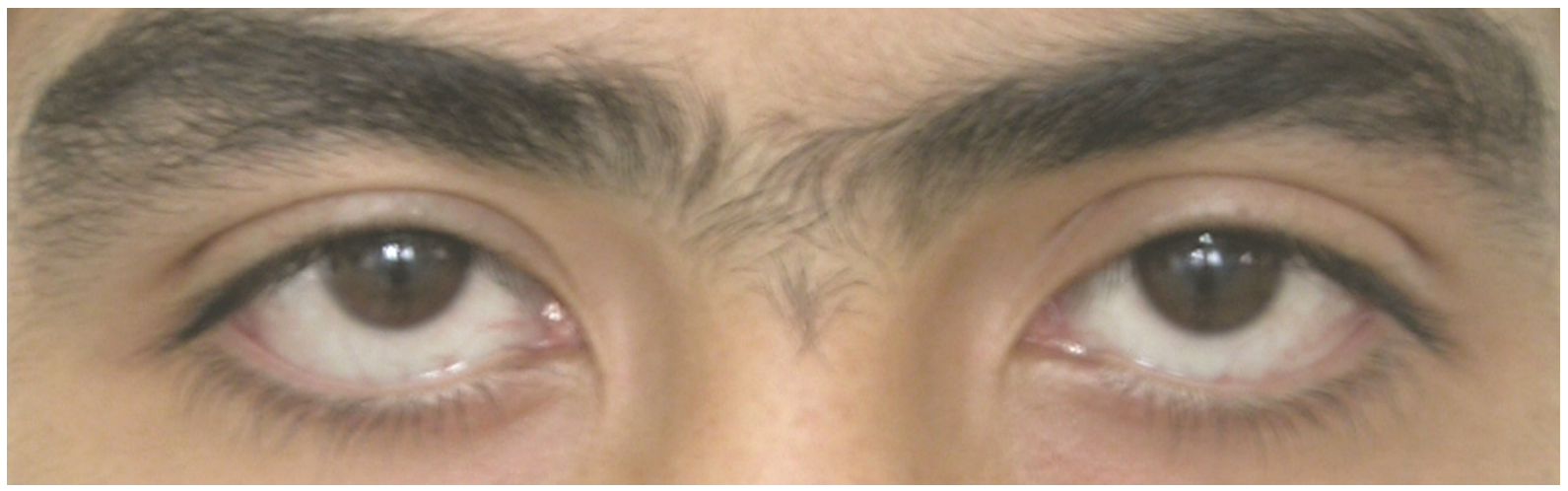

Figure 2. Bilateral bulb displacement. 


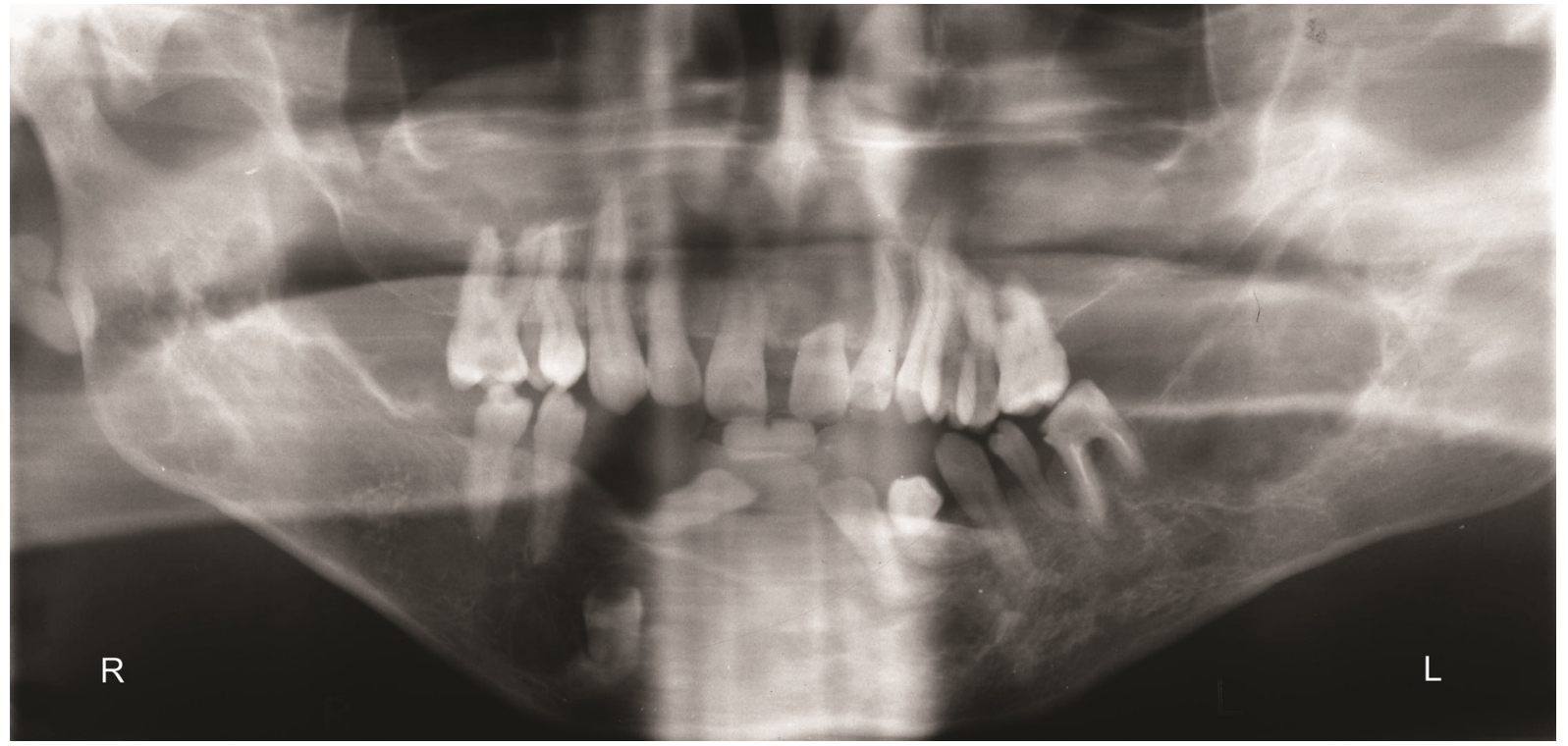

Figure 3. Panoramic radiograph before calcitonin therapy.
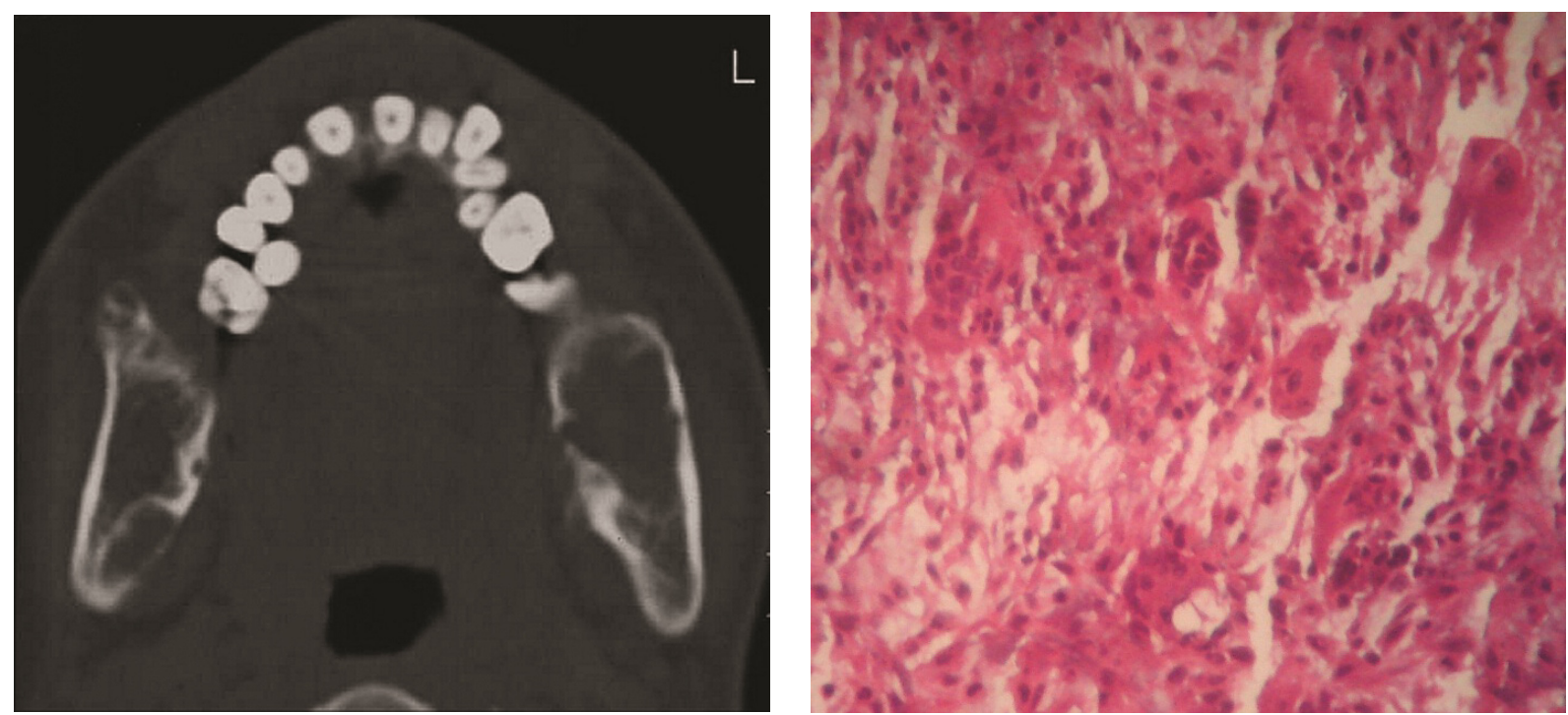

Figure 4. Computerized tomography view before calcitonin therapy.

Figure 5. Histopathologic view of the lesion (HE $\times 400)$.

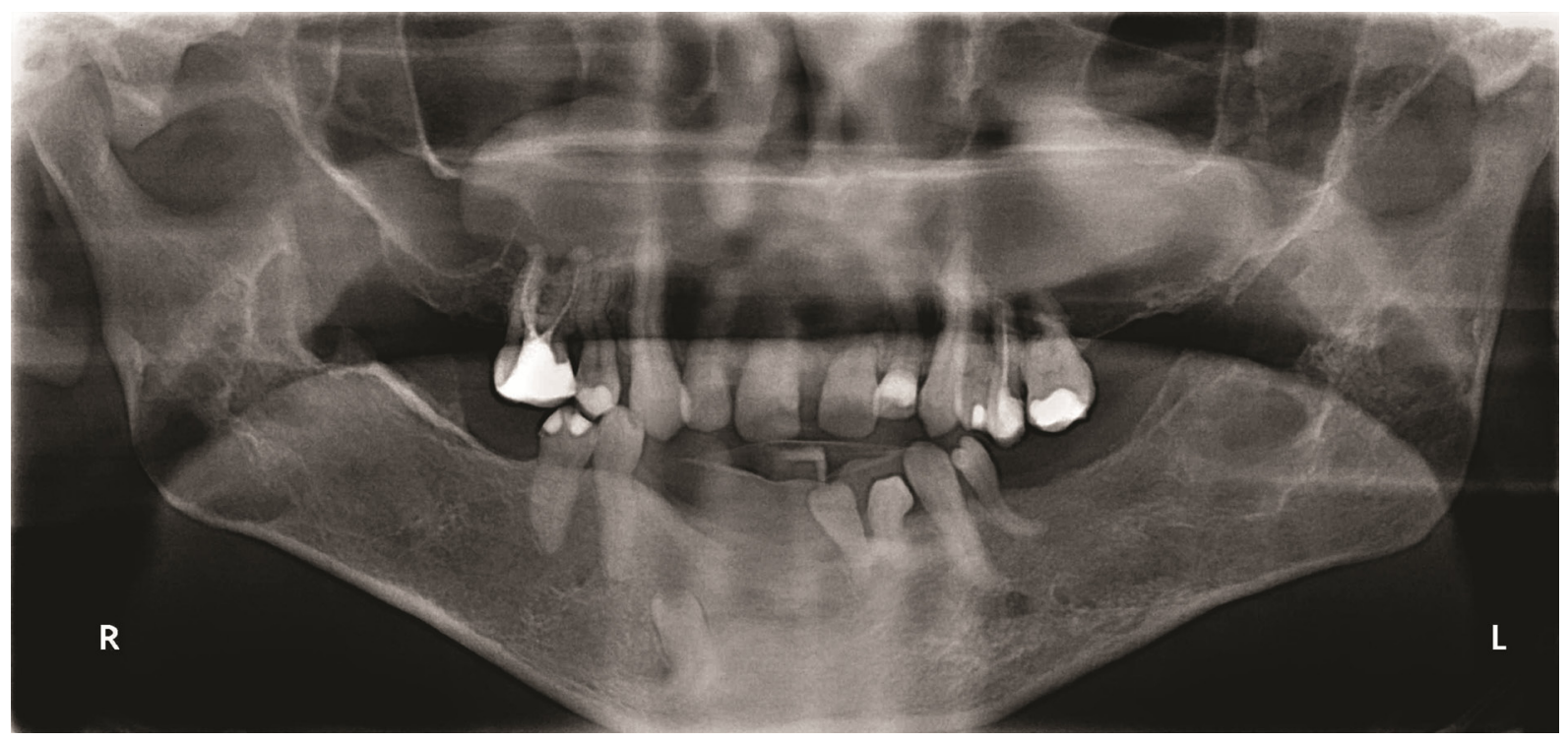

Figure 6. Panoramic radiograph after calcitonin therapy.

October 2011 - Vol.5 
CGCG, daily subcutaneous administration of human calcitonin has become the most common method of therapy. However, the use of salmon calcitonin has recently become more popular than using human calcitonin because of its increased potency and availability. ${ }^{21}$ The correct dose of calcitonin has been determined at 100 IU per day, which is based on the regimens previously used for Paget's disease..$^{22}$ On the other hand, the use of daily 200 IU salmon calcitonin via nasal spray for cherubism has been recently reported. ${ }^{2}$ In the present case, 200 IU calcitonin was administered via nasal spray every-other-day to make an equivalent daily dose of $100 \mathrm{IU}$, because a $100 \mathrm{IU}$ calcitonin nasal spray dosage was not available in the country. However, it is well known that daily subcutaneous administration of 100 IU calcitonin is considerably more effective than an every-other-day nasal dose of $200 \mathrm{IU}$. As a result, the two treatment regimens are not comparable due to the lower bio-availability of nasal spray. In general, subcutaneous application was preferred in order to achieve efficient absorption. Nevertheless, the absorbed amount of calcitonin might be unpredictable because of the condition of the nasal mucosa. However, systemic calcitonin dosage via nasal spray is considered the easiest method of management, especially in children.

To our knowledge, the present report is the second in which cherubic lesions were treated with systemic calcitonin administration via nasal spray for duration of more than one year. After approximately three years of treatment, calcitonin therapy was discontinued since radiographic regression of the lesions and growth of the patient had ended, and the patient was scheduled

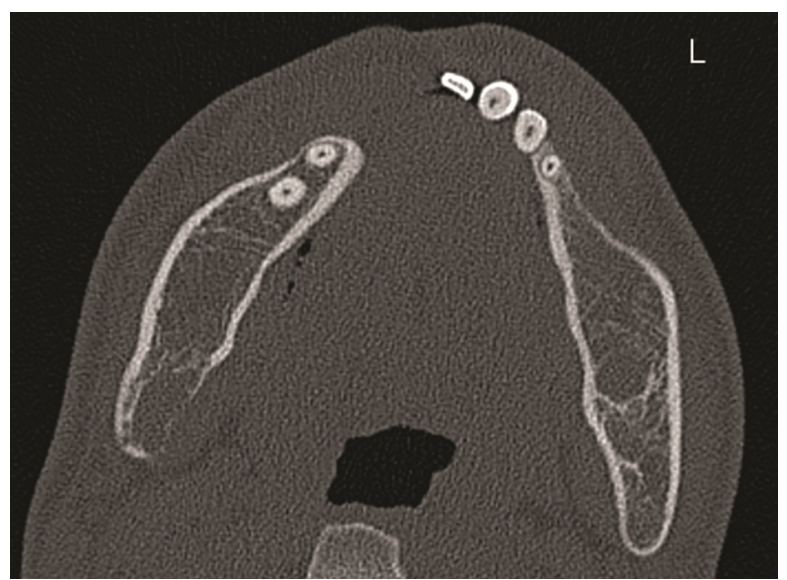

for follow-up. However, regression of the lesions through the natural course of the disease, due to the relatively older age of the patient, may have contributed to the successful outcome of the treatment. The dose and application method of calcitonin therapy would be dependent on the case and patient tolerability. A dosage of 200 IU calcitonin via nasal spray may be administered every other day in order to improve patient tolerability and continuity of the treatment, especially in mild cases of cherubism. Further studies will be necessary to determine the ideal regimen of calcitonin therapy for cherubic individuals.

\section{REFERENCES}

1. Jones WA. Familial multilocular cystic disease of the jaws. Am J Cancer 1933; 17:946.

2. De Lange J, van den Akker H, Scholtemeijer M. Cherubism treated with calcitonin: report of a case. J Oral Maxillofac Surg 2007;65:1665-1667.

3. Anderson DE, McClendon JL. Cherubism-hereditary fibrous dysplasia of the jaws; I. genetic considerations. Oral Surg Oral Med Oral Pathol 1962;15(suppl.2):5-16.

4. De Lange J, van Maarle M, van den Akker HP, Redeker EJW. A new mutation in the SH3BP2 gene showing reduced penetrance in a family affected with cherubism. Oral Surg Oral Med Oral Pathol 2007;103:378-381.

5. Gunhan 0. Oral ve Maksillofasiyal Patoloji ( $1^{\text {st }}$ edn). Ankara: Atlas Kitapcilik; 2001.

6. Carlos R, Sedano HO. Intralesional corticosteriods as an alternative treatment for central giant cell granuloma. Oral Surg Oral Med Oral Pathol 2002;93:161-166.

7. Kaban LB, Mulliken JB, Ezekowitz RA et al. Antiangiogenic therapy of a recurrent giant cell tumor of the mandible with interferon alfa-2a. Pediatrics 1999;103:1145-1149.

8. Harris M. Central giant cell granulomas of the jaws regress with calcitonin therapy. Br J Oral Maxillofac Surg 1993;31:89-94.

9. Pogrel MA. Calcitonin therapy for central giant cell granuloma. J Oral Maxillofac Surg 2003;61:649-653.

10. Von Wowern N. Cherubism: a 36-year long term follow-up of 2 generations in different families and review of the literature. Oral Surg Oral Med Oral Pathol 2000;90:765-772.

11. Hyckel P, Berndt A, Schleier P, Clement JH, Beensen V, Peters $\mathrm{H}$, et al. Cherubism - new hypotheses on pathogenesis and therapeutic consequences. J Craniomaxillofac Surg 2005;33:61-68.

12. Grünebaum $M$, Tiqva $P$. Non-familial cherubism: report of a case. J Oral Surg 1973;31:632-635.

Figure 7. Computerized tomography view after calcitonin therapy 
13. Kozakiewicz M, Perezynska-Partyka W, Kobos J. Cherubism - clinical picture and treatment. Oral Diseases 2001;7:123-130.

14. Pogrel MA, Regezi JA, Harris ST, Goldring SR. Calcitonin treatment for central giant cell granulomas of the mandible: report of two cases. J Oral Maxillofac Surg 1999;57:848853.

15. Flanagan AM, Nui B, Tinkler SMB, Horton MA, Williams DM, Chambers TJ. The multinucleate cell in giant cell granulomas of the jaw are osteoclast. Cancer 1988;62:1139-1145.

16. Southgate J, Sarma U, Townend JV, Barron J, Flanagan AM. Study of the cell biology and chemistry of cherubism. $J$ Clin Pathol 1998;51:831-837.

17. Lannon DA, Earley MJ. Cherubism and its charlatans. $\mathrm{Br} J$ Plast Surg 2001;54:708-731.

18. Hart W, Schweitzer DH, Slootweg PJ, et al. Man with cherubism. Ned Tijdschr Geneeskd 2000;144:34-38.

19. Motamedi MHK. Treatment of cherubism with locally aggressive behavior presenting in adulthood: report of four cases and a proposed new grading system. J Oral Maxillofac Surg 1998;56:1336-1342.

20. Seward GR, Hankey GT. Cherubism. Oral Surg Oral Med Oral Pathol 1957;10:952-974.

21. Azria M. The calcitonines, physiology and pharmacology. London: Karger;1989.

22. De Lange J, Rosenberg AJWP, van den Akker HP, Koole R, Wirds JJ, van den Berg. Treatment of giant cell granuloma with calcitonin. Int J Oral Maxillofac Surg 1999;28:372-376. 